\title{
Protective and reversal effects of conserved dopamine neurotrophic factor on PC12 cells following 6-hydroxydopamine administration
}

\author{
JIAMING MEI and CHAOSHI NIU \\ Department of Neurosurgery, Anhui Provincial Hospital Affiliated to Anhui Medical University, \\ Anhui Province Key Laboratory of Brain Function and Brain Disease, Hefei, Anhui 230001, P.R. China
}

Received March 1, 2014; Accepted January 22, 2015

DOI: $10.3892 / \mathrm{mmr} .2015 .3388$

\begin{abstract}
Conserved dopamine neurotrophic factor (CDNF), a member of the mammalian mesencephalic astrocyte-derived neurotrophic factor family of conserved secreted factors, has been reported to protect and rescue dopaminergic neurons in vivo. $\mathrm{PC} 12$ pheochromocytoma cells are widely used as a cell model for Parkinson's disease (PD) for experimental studies. In the present study, PC12 cells were induced using 6-hydroxydopamine (6-OHDA) to mimic PD, which was used to investigate the protective and reversal effects of CDNF against PD in vitro. Cell growth was assessed using an MTT assay, the rate of cell apoptosis was detected using flow cytometry and the apoptotic morphology of cells was observed using terminal deoxynucleotidyl transferase-mediated deoxyuridine triphosphate nick end labeling (TUNEL) staining. Pre-treatment of PC12 cells with $\operatorname{CDNF}$ (50, 100 and $200 \mathrm{nM}$ ) prior to exposure to $100 \mu \mathrm{M} 6$-OHDA for $24 \mathrm{~h}$, resulted in a significant increase in cell viability compared with that of 6-OHDA only-treated cells, with cell survival rates of 46.6, 54.7 and $69.6 \%$, respectively. In addition, PC12 cells were treated with CDNF (50, 100 and $200 \mathrm{nM}$ ) following 6-OHDA administration, which resulted in cell survival rates of 47.7, 57.6 and $57.5 \%$, respectively. Flow cytometric and TUNEL staining analyses revealed that CDNF exhibited significant dose-dependent protective and reversal effects on the apoptotic rate of PC12 cells following 6-OHDA treatment. In conclusion, the results of the present study showed that CDNF exhibited neuroprotective and reversal effects on the 6-OHDA-induced apoptosis of PC12 cells in a dose-dependent manner.
\end{abstract}

Correspondence to: Dr Jiaming Mei, Department of Neurosurgery, Anhui Provincial Hospital Affiliated to Anhui Medical University, Anhui Province Key Laboratory of Brain Function and Brain Disease, 17 Lujiang Road, Hefei, Anhui 230001, P.R. China E-mail: doctorstar@126.com

Key words: conserved dopamine neurotrophic factor, dopaminergic neurons, Parkinson's disease, neuroprotective and reversal effects

\section{Introduction}

Parkinson's disease (PD) is a prevalent neurodegenerative disease, which is neuropathologically characterized by the loss of substantia nigra pars compacta $(\mathrm{SNpc})$ dopaminergic neurons, resulting in disabling motor abnormalities $(1,2)$. Numerous studies have explored the pathogenesis of PD; however, the etiology of PD remains to be fully elucidated. Previous studies have indicated that mitochondrial dysfunction upregulates the production of reactive oxygen species (ROS), which initiates the neurodegeneration of dopaminergic cells in vivo and in vitro (3-6). 6-Hydroxydopamine (6-OHDA), a hydroxylated analogue of dopamine, was reported to induce ROS degeneration, therefore resulting in models of PD in vivo and in vitro (1,7-9). PC12 rat pheochromocytoma cells, derived from rat pheochromocytoma tumors, have numerous properties that are similar to those of dopaminergic neurons and are therefore widely used for studies investigating the pathogenesis and treatment of PD (10-12). In the present study, PC12 cells exposed to 6-OHDA served as a typical experimental model for the investigation of PD in vitro.

Conserved dopamine neurotrophic factor (CDNF), a member of the mammalian mesencephalic astrocyte-derived neurotrophic factor family, has been reported to significantly protect and reverse the loss of dopaminergic neurons due to 6-OHDA treatment in vivo, through the direct infusion of CDNF proteins or CDNF-engineered vectors into the brain (2,13-16). The present study aimed to investigate whether CDNF exhibited comparable neuroprotective and reversal effects in 6-OHDA-treated $\mathrm{PC1} 2$ cells in vitro.

\section{Materials and methods}

Harvesting and identification of CDNF protein production. Total RNA was isolated from mouse heart and skeletal muscle using TRIzol ${ }^{\circledR}$ reagent (Invitrogen Life Technologies, Carlsbad, CA, USA). First-strand cDNA was synthesized using SuperscriptII reverse transcriptase (Invitrogen Life Technologies) and then amplified through polymerase chain reaction (PCR). Recombinant mouse CDNF (pFastBacHTb-mCDNF) labeled with Flag and 6X His tags (Invitrogen Life Technologies) was produced through 
baculoviral expression in Sf9 insect cells (Invitrogen Life Technologies), as described previously (12). Secreted CDNF was purified from culture supernatants using nickel affinity chromatography followed by anion exchange chromatography. Rats were kept at the Anhui Province Key Laboratory of Brain Function \& Brain Disease (Anhui, China) and all experimental procedures were performed in accordance with the Guidelines for Animal Care and Use of the National Institutes of Health. The present study was approved by the Ethical Commttee of Anhui Provincial Hospital (Anhui, China).

Cell culture and drug treatment. PC12 cells were obtained from the Shanghai Institute of Cell Biology, Chinese Academy of Sciences (Shanghai, China), and maintained in Dulbecco's modified Eagle's medium (DMEM; Santa Cruz Biotechnology, Inc., Dallas, TX, USA). Cells were treated with 6-OHDA (Beijing Zhongshan Golden Bridge Biotechnology Co., Ltd., Beijing, China) at concentrations of 1, 2.5, 5, 25, 50,100 and $150 \mu \mathrm{M}$ and then cultured for $24 \mathrm{~h}$ in order to determine the optimal concentration of 6-OHDA for inducing PD model cells. PC12 cells were pre- or post-incubated with 50, 100 and $200 \mathrm{nM} \mathrm{CDNF}$ protein in order to investigate the protective and reversal effects of CNDF protein on 6-OHDA-induced neurotoxicity. The groups used in the present study were as follows: A, control; B, 6-OHDA treatment only; C, 6-OHDA + CDNF pre-treatment; and $\mathrm{D}, 6-\mathrm{OHDA}+\mathrm{CDNF}$ post-treatment.

MTT assay. Cell viability was measured using a colorimetric MTT assay. This method involves the cleavage of a yellow tetrazolium salt into a purple formazan compound through the dehydrogenase activity of intact mitochondria. In brief, cells were washed once with phosphate-buffered saline (PBS) prior to the addition of $0.1 \mathrm{ml}$ serum-free medium containing MTT (1 mg/ml; Sigma-Aldrich, St. Louis, MO, USA) to each well. Following incubation for $3 \mathrm{~h}$, the supernatant was removed and the formazan product obtained was dissolved in $1 \mathrm{ml}$ dimethylsulfoxide (Sigma-Aldrich) and incubated for 15 min with agitation on a microtiter plate shaker (CFJ-II; Shanghai Lei Yun Test Instrument Manufacturing Co., Ltd., Shanghai, China). The absorbance was then measured at $570 \mathrm{~nm}$ using an enzyme immunoassay instrument (DG5031; Shanghai Kehuai Instrument Co., Ltd, Shanghai, China). Cell viability was expressed as a percentage of that of the untreated cells, which served as the control group.

Terminal deoxynucleotidyl transferase-mediated deoxyuridine triphosphate-mediated nick end labeling (TUNEL) staining. A TUNEL kit was purchased from Roche Diagnostics (Basel, Switzerland). Following $24 \mathrm{~h}$ of culture under the experimental conditions described above, $\mathrm{PC} 12$ cells were fixed with $4 \%$ paraformaldehyde in $0.1 \mathrm{M}$ phosphate buffer $(\mathrm{pH}$ 7.4) for $1 \mathrm{~h}$. Cells were then washed with PBS, treated with $0.3 \% \mathrm{H}_{2} \mathrm{O}_{2}$ in methanol for $10 \mathrm{~min}$ and then washed with $0.1 \%$ sodium citrate containing 0.1\% Triton X-100 (Santa Cruz Biotechnology, Inc.). In order to detect nuclear DNA fragmentation, the TUNEL reagent was applied to the fixed cells. In brief, cells were incubated with $50 \mu$ l terminal deoxynucleotidyl transferase (TdT) solution ( $45 \mu$ l equilibration buffer, $1 \mu \mathrm{l}$ biotin-11-deoxyuridine triphosphate and $4 \mu 1$ TdT enzyme; Beijing Zhongshan Golden

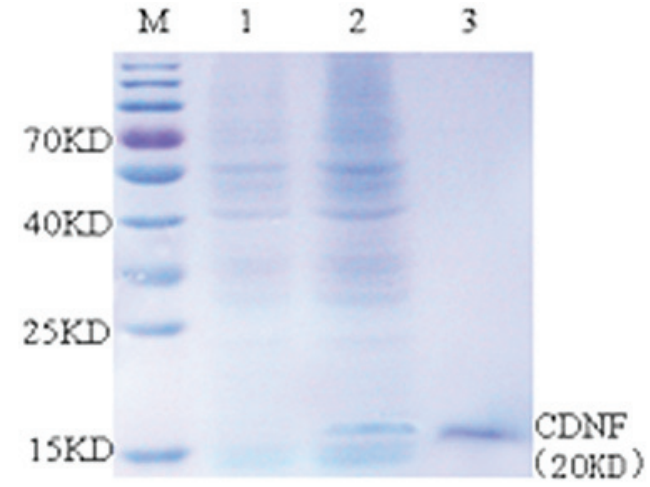

Figure 1. Reverse transcription-polymerase chain reaction was performed on conserved dopamine neurotrophic factor. Lane M, molecular weight protein markers; lane 1, control Sf9 supernatant; lane 2, supernatant from CDNF-expressing Sf9 cells; and lane 3, CDNF protein (20 kDa) eluted following nickel exchange chromatography.

Bridge Biotechnology Co., Ltd, Beijing, China) in the dark, in a humid atmosphere at $37^{\circ} \mathrm{C}$ for $60 \mathrm{~min}$. Samples were then further incubated with $50 \mu \mathrm{l}$ streptavidin-horseradish peroxidase (HRP) solution (0.5 $\mu 1$ streptavidin-HRP and $99.5 \mu 1$ PBS; Beijing Zhongshan Golden Bridge Biotechnology Co., Ltd) in the dark for $30 \mathrm{~min}$ at room temperature. In order to determine the rate of cell death, staining for peroxidase was performed using $100 \mu \mathrm{l}$ diaminobenzidine (DAB) solution (5 $\mu \mathrm{l}$ of 20X DAB, $1 \mu \mathrm{l}$ of $30 \% \mathrm{H}_{2} \mathrm{O}_{2}$ and $94 \mu \mathrm{l}$ PBS; Beijing Zhongshan Golden Bridge Biotechnology Co., Ltd) for $10 \mathrm{~min}$. All samples were washed three times with PBS and then observed under a microscope (BX51; Olympus, Tokyo, Japan) in order to count the positive-stained cells. A minimum of ten fields were observed and $>1,000$ cells were counted in order to determine a statistically significant percentage of apoptotic cells. Data were expressed as a percentage of the control group, which was designated as $100 \%$.

Apoptosis by flow cytometry analysis. In order to detect 6-OHDA-induced early apoptosis and late apoptosis/necrosis in the presence or absence of CDNF treatment. The collected media was centrifuged at $1,500 \mathrm{x}$ g for $5 \mathrm{~min}$ and then supernatants placed at $-80^{\circ} \mathrm{C}$ until further use for in vitro assays. PC12 cells $\left(2 \times 10^{5} /\right.$ well $)$ were seeded onto six-well plates and cells in the corresponding groups were treated with CDNF. Cells were then harvested through centrifugation at $1,500 \mathrm{x}$ g for $5 \mathrm{~min}$, fixed with $70 \%$ ethanol (in PBS) at $4^{\circ} \mathrm{C}$ overnight. Cells were then resuspended in PBS, containing $40 \mu \mathrm{g} / \mathrm{ml}$ propidium iodide (Invitrogen Life Technologies), $0.1 \mathrm{mg} / \mathrm{ml}$ R Nase (Invitrogen Life Technologies) and $0.1 \%$ Trixon X-100, and incubated in the dark for $30 \mathrm{~min}$ at $37^{\circ} \mathrm{C}$. Cells were analyzed using a FACSCalibur flow cytometer (Becton-Dickinson, San Jose, CA, USA) with an argon ion laser at $488 \mathrm{~nm}$. Data were collected using Cell Quest software (Becton-Dickinson).

Statistical analysis. Values are expressed as the mean \pm standard error of the mean. Statistical analysis between two groups was performed using Student's t-test with SPSS 13.0 software (SPSS, Inc., Chicago, IL, USA). P $<0.05$ was considered to indicate a statistically significant difference between values. 


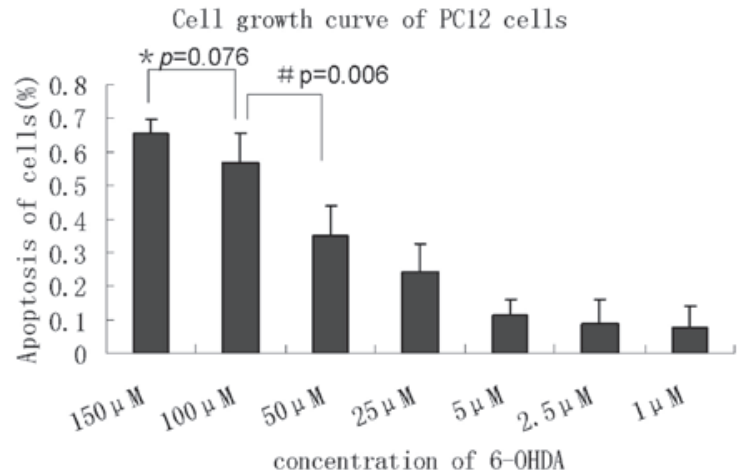

Figure 2.6-OHDA-induced apoptosis in $\mathrm{PC} 12$ cells. ${ }^{*} \mathrm{P}=0.076 \mathrm{vs.} 150 \mu \mathrm{M} 6-\mathrm{OHDA}$ and ${ }^{\#} \mathrm{P}=0.006$ vs. $50 \mu \mathrm{M}$ 6-OHDA. 6-OHDA, 6-Hydroxydopamine.

A
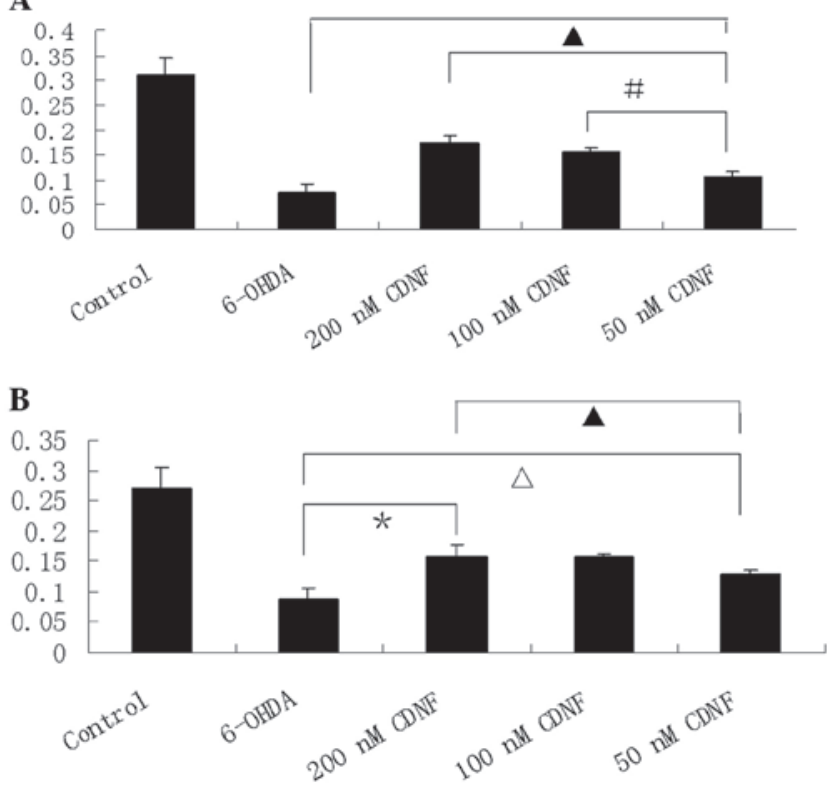

Figure 3.Pre- and post-treatment with CDNF protects and reverses the effect of 6-OHDA on $\mathrm{PC} 12$ cell viability. Cell viability of $\mathrm{PC} 12$ cells following treatment with CDNF (A) prior to 6-OHDA exposure for $24 \mathrm{~h}$ (" $\mathrm{P}=0.000$ vs. 6-OHDA only; ${ }^{\wedge} \mathrm{P}=0.006$ vs. $200 \mathrm{nM} \mathrm{CDNF} ;{ }^{*} \mathrm{P}=0.008$ vs. $100 \mathrm{nM}$ CDNF) or (B) following 6-OHDA exposure for $24 \mathrm{~h}\left({ }^{*} \mathrm{P}=0.015\right.$ or ${ }^{\triangle} \mathrm{P}=0.032$ vs. 6-OHDA ${ }^{\triangle} \mathrm{P}=0.103$ vs. $200 \mathrm{nM}$ CDNF). CDNF, conserved dopamine neurotrophic factor; 6-OHDA, 6-hydroxydopamine.

\section{Results}

Harvesting and identifying CDNF. Total RNA was extracted from mouse heart and skeletal muscle, mouse CDNF cDNA was then reverse transcribed and amplified using PCR. Recombinant CDNF was produced using a baculovirus expression system in Sf9 cells, where CDNF was secreted into the culture medium and then purified (Fig. 1).

Cell viability of 6-OHDA-induced PC12 cells. In order to investigate the effect of 6-OHDA on cell viability in PC12 cells, the cells were incubated with 6-OHDA at concentrations of $1,2.5,5,25,50,100$ and $150 \mu \mathrm{M}$ and then cultured for $24 \mathrm{~h}$. The viability of PC12 cells was then measured using an MTT assay. As shown in Fig. 2, at concentrations $<25 \mu \mathrm{M}$, 6-OHDA exhibited no significant effect on apoptosis in PC12
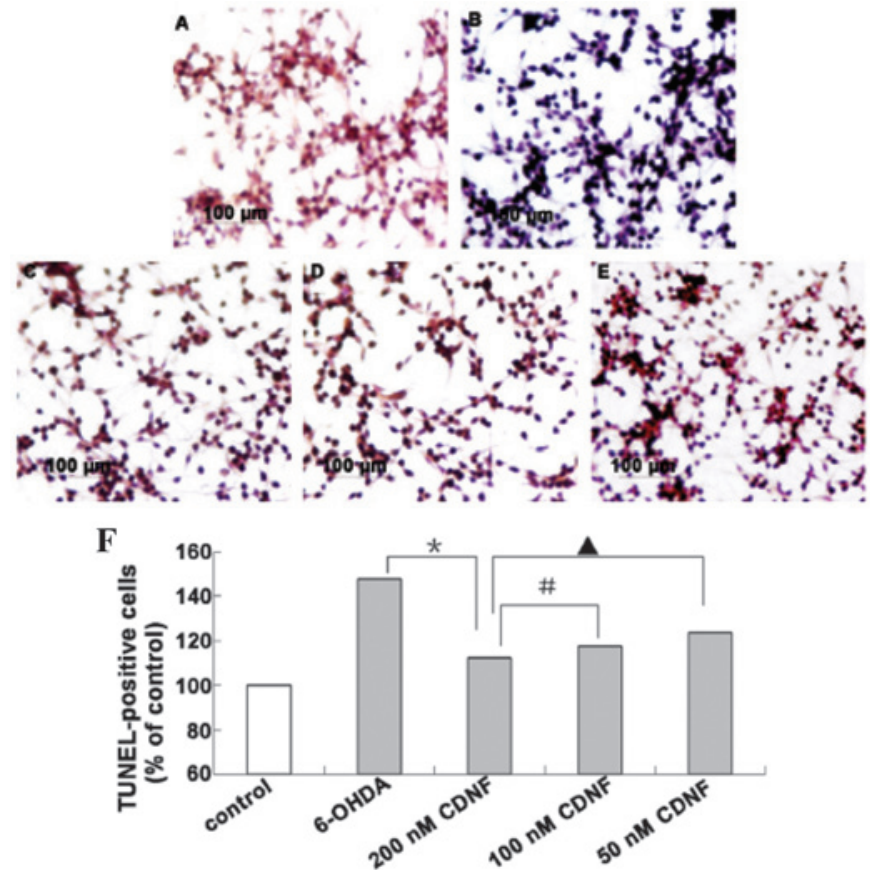

Figure 4. Protective effects of CDNF on 6-OHDA-induced apoptosis in PC12 cells. In order to detect apoptosis, TUNEL-staining was performed in PC12 cells treated as follows: (A) Control; (B) $100 \mu \mathrm{M} 6-\mathrm{OHDA}$; and (C) 200, (D) 100 and (E) $50 \mathrm{nM}$ CDNF pre-treatment, respectively, followed by $100 \mu \mathrm{M}$ 6-OHDA. (F) Percentage of TUNEL-positive cells compared with that of the control cultures. Values are presented as the mean \pm standard error of them mean. ${ }^{*} \mathrm{P}<0.05$ vs. 6 -OHDA only; ${ }^{*} \mathrm{P}>0.05$ and $\mathbf{\Delta}<<0.05$ vs. $200 \mathrm{nM}$ CDNF. CDNF, conserved dopamine neurotrophic factor; 6-OHDA, 6-hydroxydopamine; TUNEL, terminal deoxynucleotidyl transferase deoxyuridine triphosphate-mediated nick end labeling.

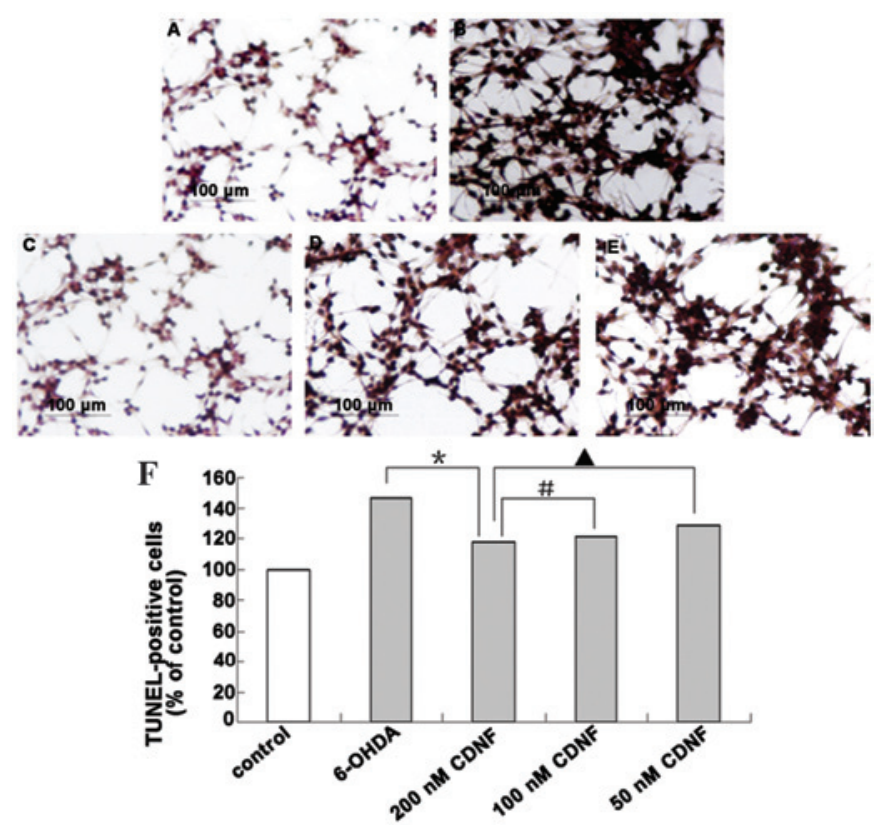

Figure 5. Reversal effects of CDNF on 6-OHDA-induced apoptosis in PC12 cells. In order to detect apoptosis, TUNEL-staining was performed in PC12 cells treated as follows: (A) Control; (B) $100 \mu \mathrm{M} 6$-OHDA; (C-E) $100 \mu \mathrm{M}$ 6-OHDA followed by 200, 100 and $50 \mathrm{nM}$ CDNF post-treatment, respectively. (F) Percentage of TUNEL-positive cells compared with that of the control cultures. Values are presented as the mean \pm standard error of them mean. ${ }^{~} \mathrm{P}<0.05$ vs. 6 -OHDA only; ${ }^{*} \mathrm{P}>0.05$ and $\boldsymbol{\Delta}^{\mathrm{P}}<0.05$ vs. $200 \mathrm{nM}$ CDNF. CDNF, conserved dopamine neurotrophic factor; 6-OHDA, 6-hydroxydopamine; TUNEL, terminal deoxynucleotidyl-mediated transferase deoxyuridine triphosphate nick end labeling. 


\section{A}
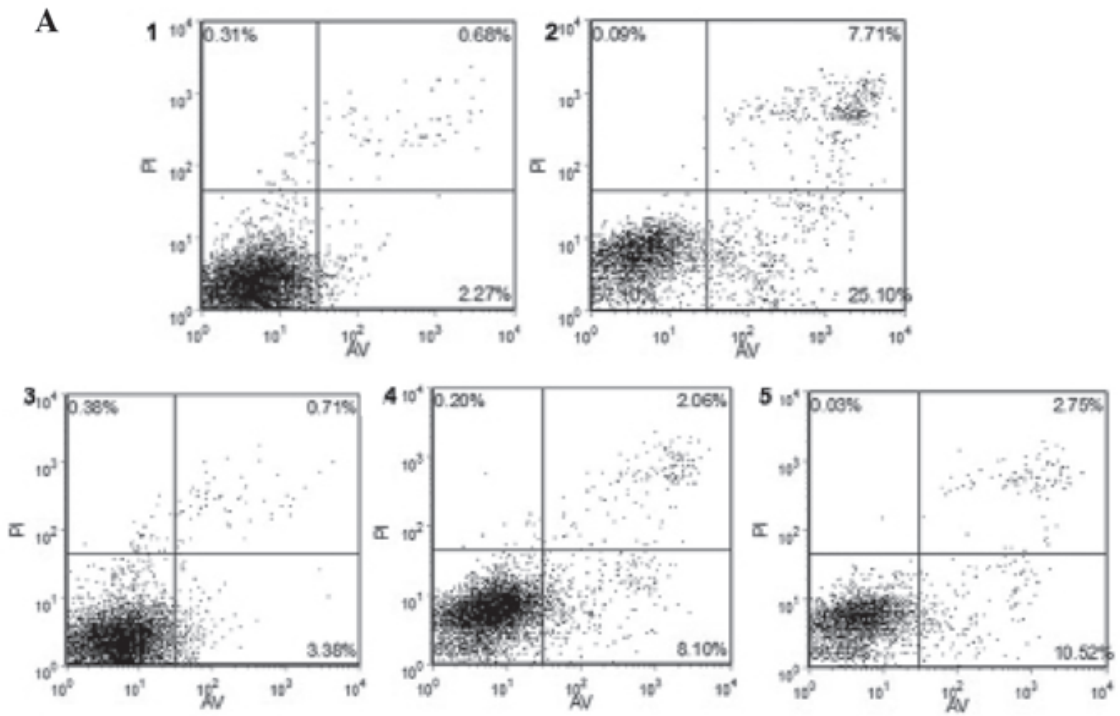

B
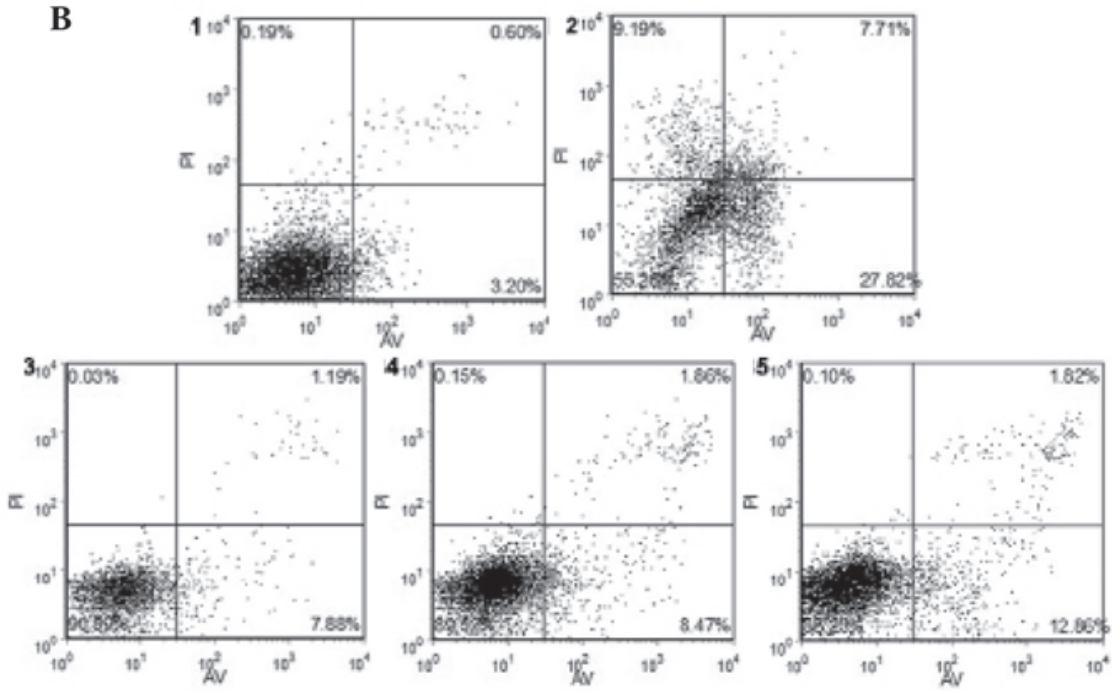

Figure 6. Flow cytometric analysis of PC12 cell apoptosis. PC12 cells were treated with CDNF (A) prior to and (B) following culture with 6-OHDA for $24 \mathrm{~h}$. Cell groups were as follows: 1, control; 2, $100 \mu \mathrm{M}$ 6-OHDA; 3-5, $100 \mu \mathrm{M}$ 6-OHDA with pre- or post-treatment with 200, 100 and $50 \mathrm{nM}$ CDNF, respectively. CDNF, conserved dopamine neurotrophic factor; 6-OHDA, 6-hydroxydopamine.

cells. However, significant increases in 6-OHDA-induced apoptosis occurred in a dose-dependent manner at concentrations $\geq 25 \mu \mathrm{M}$ in $\mathrm{PC} 12$ cells. In addition, there was a marked increase in apoptosis between 50 and $100 \mu \mathrm{M}(\mathrm{P}=0.006)$, which resulted in the apoptotic rate exceeding $50 \%$ at $100 \mu \mathrm{M}$. Although no significant increase was observed between 100 and $150 \mu \mathrm{M}(\mathrm{P}=0.076)$, the number of necrotic cells in the $150 \mu \mathrm{M}$ group was observably increased (Data not shown), which would interfere with the investigation of the reversal effect of CDNF protein. Therefore, in order to reduce the toxicity of 6-OHDA, $100 \mu \mathrm{M}$ was deemed the optimal experimental concentration (Fig. 2).

CDNF exerts protective and reversal effects on 6-OHDA-induced PC12 cell viability. PC12 cell viability was determined using an MTT assay. Following treatment with 6-OHDA alone $(100 \mu \mathrm{M})$, cell viability was significantly reduced $(21.8 \%)$ compared with that of the control group. CDNF treatment $(50,100$ and $200 \mathrm{nM})$ for $30 \mathrm{~min}$ prior to 6-OHDA $(100 \mu \mathrm{M})$ exposure for $24 \mathrm{~h}$ resulted in the significant increase of $\mathrm{PC} 12$ cell viability compared with that of the 6-OHDA alone treatment, with survival rates of 46.6, 54.7 and $69.6 \%$ of control, respectively (Fig. 3A). In addition, $\mathrm{PC} 12$ cells incubated with CDNF following exposure to 6-OHDA for $24 \mathrm{~h}$ demonstrated a significant increase in cell viability compared with that of those treated with 6-OHDA alone, with survival rates of 47.7, 57.6 and $57.5 \%$ of control, respectively (Fig. 3B). These data therefore indicated that CDNF prevented and reversed the effects of 6-OHDA on cell viability.

Attenuation of 6-OHDA-induced apoptosis by CDNF. A distinctive biochemical characteristic of apoptotic cell death is the occurrence of internucleosomal DNA fragmentation. In the present study, apoptotic cells were assessed using TUNEL staining, a widely used method for detecting DNA fragmentation in situ. As shown in Fig. 4 and 5, following exposure to $100 \mu \mathrm{M}$ 6-ODHA, the number of TUNEL-positive PC12 cells was significantly increased compared with that of the control group $(\mathrm{P}<0.05)$. In addition, the anti-apoptotic effects 
of CDNF (200, 100 and $50 \mathrm{nM})$ were examined in PC12 cells prior to and following 6-OHDA-induced apoptosis. As shown in Fig. 4, treatment of PC12 cells with CDNF (200, 100 and $50 \mathrm{nM}$ ) for $30 \mathrm{~min}$ prior to 6-OHDA exposure for $24 \mathrm{~h}$ resulted in a significant decrease in the number of TUNEL-positive cells compared with that of the 6-OHDA only group, with apoptotic rates of $112.47 \%, 117.87 \%$ and $123.65 \%$ of control, respectively. Furthermore, when incubated with CDNF following exposure to 6-OHDA for $24 \mathrm{~h}$, the number of TUNEL-positive cells was also markedly decreased compared with that of the 6-OHDA only group, with apoptotic rates of $116.98 \%, 121.65$ and $128.12 \%$ of control, respectively (Fig. 5).

Flow cytometric analysis of the effects of CDNF on 6-OHDA-induced apoptosis in PC12 cells. In order to examine the effects of 6-OHDA and CDNF on apoptosis in PC12 cells, flow cytometric analysis was performed. The results showed that following treatment with 6-OHDA alone, $\sim 39.79 \%$ of cells were apoptotic at $24 \mathrm{~h}$; however, pre-treatment of 6-OHDA-induced PC12 cells with CDNF (200, 100 and $50 \mathrm{nM}$ ) significantly reduced the apoptotic rates to $5.62,10.36$ and $13.31 \%$, respectively (Fig. 6A). In addition, following incubation with CDNF protein $(200,100$ and $50 \mathrm{nM})$ post-exposure to 6-OHDA for $24 \mathrm{~h}$ resulted in significantly decreased apoptotic rates of $9.1 \%, 10.48 \%$ and $14.78 \%$, respectively (Fig. 6B).

\section{Discussion}

The present study demonstrated that 6-OHDA induced the decrease of PC12 cell viability to $21.8 \%$, which was in accordance with a previous study by Gorman et al (17). In addition, the present study demonstrated that CDNF prevented and reversed the effect of 6-OHDA on PC12 cell apoptosis in a dose-dependent manner, suggesting a neuroprotective function in neuronal cells in vitro.

Previous studies have elucidated that neurotrophic factors, including BDNF and GDNF, may prevent neurodegeneration $(18,19)$. In addition, GDNF was previously reported to improve symptoms in patients with PD; however, this potential treatment was found to have serious adverse effects and low clinical benefit (20-22). These findings encouraged novel studies into potential neurotrophic factors that may slow down or reverse the progression of neuronal degeneration. Lindholm et al (13) reported that CDNF exerted neuroprotective and reversed the neurodegenerative effects of dopaminergic neurons in vivo, which significantly decreased the loss of dopaminergic neurons in rat models induced by 6-OHDA and 1-methyl-4-phenyl-1,2,3,6-tetrahydropyridine, at the pathological and behavioral levels $(2,13,14)$. The aim of the present study was to evaluate the neuroprotective effects of CDNF in vitro. $\mathrm{PC} 12$ cells pre-cultured with CDNF prior to 6-OHDA treatment exhibited increased cell viability, in a dose-dependent manner, as detected using an MTT assay. The maximum protective effect on cell viability was observed at a pre-culture concentration of $200 \mathrm{nM}$ CDNF, which increased cell viability to $69.6 \%$. In addition, pre-treatment with CDNF decreased the number of TUNEL-positive cells and the apoptotic rate of PC12 cells in a dose-dependent manner. Furthermore, in the present study, PC12 cells were cultured with 6-OHDA for $24 \mathrm{~h}$ and then post-treated with various concentrations of CDNF. These results showed that cell viability was also increased compared with that of the control group. In addition, the reversal effects of CDNF were detected using TUNEL-staining and flow cytometry; however, the protective effects were marginally inferior to those of the CDNF pre-treatment. By contrast, the neuroprotective effect on cell viability of CDNF in vitro $(200 \mathrm{nM}$, $69.6 \%$ ) was markedly less potent than the reported effect of CDNF in vivo (96\%) (13). The explanation for this may be due to the fact that the PC12 cell model induced using 6-OHDA is an acute model of PD, which is not completely consistent with the chronic progress of neurodegeneration in vivo (23-25). In addition, single cell models do not replicate the survival microenvironment of dopaminergic neurons in vivo. Another explanation may be that CDNF proteins stimulate other cytokines or signal pathways, which may be involved in neuroprotection in vivo. Notably, in the present study, the reversal effect of post-treatment with CDNF on cell viability ( $200 \mathrm{nM}, 57.5 \%)$ was comparable to that of the reported effect in vivo (58\%) (13). This may be attributed to the fact that 6-OHDA treatment led to later stages of apoptosis and necrosis in the PC12 cells pre-cultured with 6-OHDA, as shown in Fig. 5, whereas the earlier stages of apoptosis were more prominent following pre-treatment with CDNF. This therefore indicated that $\mathrm{CDNF}$ was unable to reverse the late stages of apoptosis and necrosis in PC12 cells.

Furthermore, the results of the present study also demonstrated that the preventive and reversal effects of CDNF occurred in a dose-dependent manner, regardless of pre- and post-incubation, which was consistent with those of other neurotrophic factors $(26,27)$. In addition, the cell morphology observed by TUNEL-staining and cell apoptosis as determined using flow cytometry also demonstrated the dose-dependent neuroprotective and reversal effects of CDNF; in particular, the effects of CDNF on the protection against early apoptosis.

In conclusion, the results of the present study showed that CDNF exerted neuroprotective and reversal effects on 6-OHDA-induced PC12 cells in a dose-dependent manner. Therefore CDNF may have therapeutic potential for PD.

\section{Acknowledgements}

The present study was supported by grants from the Foundation of the Department of Education of Anhui Province (grant no. KJ2010B381), the Foundation of Natural Science of Anhui Province (grant no. 11040606Q11) and the National Natural Science Fund (grant no. 81100960).

\section{References}

1. Han B, Hu J, Shen J, Gao Y, Lu Y and Wang T: Neuroprotective effect of hydroxysaffloryellow A on 6-hydroxydopamine-induced Parkinson's disease in rats. Eur J Pharmacol 714: 83-88, 2013.

2. Airavaara M, Harvey BK, Voutilainen MH, et al: CDNF protects the nigrostriatal dopamine system and promotes recovery after MPTP treatment in mice. Cell Transplant 21: 1213-1223, 2012.

3. Chaturvedi RK and Flint Beal M: Mitochondrial diseases of the brain. Free Radic Biol Med 63: 1-29, 2013.

4. Lopert P, Day BJ and Patel M: Thioredoxin reductase deficiency potentiates oxidative stress, mitochondrial dysfunction and cell death in dopaminergic cells. PLoS One 7: e50683, 2012. 
5. Cantu D, Fulton RE, Drechsel DA and Patel M: Mitochondrial aconitase knockdown attenuates paraquat-induced dopaminergic cell death via decreased cellular metabolism and release of iron and $\mathrm{H}_{2} \mathrm{O}_{2}$. J Neurochem 118: 79-92, 2011.

6. Calabrese V, Lodi R and Tonon C, et al: Oxidative stress, mitochondrial dysfunction and cellular stress response in Friedreich's ataxia. J Neurol Sci 233: 145-162, 2005.

7. Prinz A, Selesnew LM, Liss B, Roeper J and Carlsson T: Increased excitability in serotonin neurons in the dorsal raphe nucleus in the 6-OHDA mouse model of Parkinson's disease. Exp Neurol 248: 236-245, 2013

8. Sadan O, Bahat-Stromza M, Barhum Y, et al: Protective effects of neurotrophic factor-secreting cells in a 6-OHDA rat model of Parkinson disease. Stem Cells Dev 18: 1179-1190, 2009.

9. Olds ME, Jacques DB and Kpoyov O: Behavioral/neurophysiological investigation of effects of combining a quinolinic acid entopeduncular lesion with a fetal mesencephalic tissue transplant in striatum of the 6-OHDA hemilesioned rat. Synapse 49: 1-11, 2003.

10. Offen D, Sherki Y, Melamed E, Fridkin M, Brenneman DE and Gozes I: Vasoactive intestinal peptide (VIP) prevents neurotoxicity in neuronal cultures: relevance to neuroprotection in Parkinson's disease. Brain Res 854: 257-262, 2000.

11. Wang LZ, Sun WC and Zhu XZ: Ethyl pyruvate protects PC12 cells from dopamine-induced apoptosis. Eur J Pharmacol 508 57-68, 2005.

12. Chagkutip J, Govitrapong P, Klongpanichpak S and Ebadi M: Mechanism of 1-methyl-4-phenylpyridinium-induced dopamine release from PC12 cells. Neurochem Res 30: 633-639, 2005.

13. Lindholm P, Voutilainen MH, Laurén J, et al: Novel neurotrophic factor CDNF protects and rescues midbrain dopamine neurons in vivo. Nature 448: 73-77, 2007.

14. Voutilainen MH, Bäck S, Peränen J, et al: Chronic infusion of CDNF prevents 6-OHDA-induced deficits in a rat model of Parkinson's disease. Exp Neurol 228: 99-108, 2011.

15. Bäck S, Peränen J, Galli E, et al: Gene therapy with AAV2-CDNF provides functional benefits in a rat model of Parkinson's disease. Brain Behav 3: 75-88, 2013.

16. Ren X, Zhang T, Gong X, Hu G, Ding W and Wang $X$ : AAV2-mediated striatum delivery of human CDNF prevents the deterioration of midbrain dopamine neurons in a 6-hydroxydopamine induced parkinsonian rat model. Exp Neurol 248 148-156, 2013.
17. Gorman AM, Szegezdi E, Quigney DJ and Samali A: Hsp27 inhibits 6-hydroxydopamine-induced cytochrome c release and apoptosis in PC12 cells. Biochem Biophys Res Commun 327: 801-810, 2005.

18. Stahl K, Mylonakou MN, Skare $\varnothing$, Amiry-Moghaddam M and Torp R: Cytoprotective effects of growth factors: BDNF more potent than GDNF in an organotypic culture model of Parkinson's disease. Brain Res 1378: 105-118, 2011.

19. Gyárfás T, Knuuttila J, Lindholm P, Rantamäki T and Castrén E: Regulation of brain-derived neurotrophic factor (BDNF) and cerebral dopamine neurotrophic factor (CDNF) by anti-parkinsonian drug therapy in vivo. Cell Mol Neurobiol 30: 361-368, 2010.

20. Gill SS, Patel NK, Hotton GR, O'Sullivan K, et al: Direct brain infusion of glial cell line-derived neurotrophic factor in parkinson disease. Nat Med 9: 589-595, 2003.

21. Patel NK, Bunnage M, Plaha P, Svendsen CN, Heywood P and Gill SS: Intraputamenal infusion of glia cell line-derived neurotrophic factor in PD: a two-year outcome study. Ann Neurol 57: 298-302, 2005.

22. Lang AE, Gill S, Patel NK, et al: Randomized controlled tria of intraputamenal glial cell line-derived neurotrophic factor infusion in Parkinson disease. Ann Neurol 59: 459-466, 2006.

23. Black YD, Xiao D, Pellegrino D, Kachroo A, Brownell AL and Schwarzschild MA: Protective effect of metabotropic glutamate mGluR5 receptor elimination in a 6-hydroxydopamine model of Parkinson's disease. Neurosci Lett 486: 161-165, 2010.

24. Winner B, Desplats P, Hagl C, et al: Dopamine receptor activation promotes adult neurogenesis in an acute Parkinson model. Exp Neurol 219: 543-552, 2009.

25. Kwon IH, Choi HS, Shin KS, et al: Effects of berberine on 6-hydroxydopamine-induced neurotoxicity in PC12 cells and a rat model of Parkinson's disease. Neurosci Lett 486: 29-33, 2010

26. Kim Y, Li E and Park S: Insulin-like growth factor-1 inhibits 6-hydroxydopamine-mediated endoplasmic reticulum stress-induced apoptosis via regulation of heme oxygenase-1 and Nrf2 expression in PC12 cells. Int J Neurosci 122: 641-649, 2012.

27. Li X, Peng C, Li L, Ming M, Yang D and Le W: Glial cell-derived neurotrophic factor protects against proteasome inhibition-induced dopamine neuron degeneration by suppression of endoplasmic reticulum stress and caspase-3 activation. J Gerontol A Biol Sci Med Sci 62: 943-950, 2007. 